\title{
Esboço de uma Antropologia Filosófica Americana
}

\author{
Magali Mendes de Menezes' \\ Neusa Vaz e Silva" \\ Leonardo Castro Dorneles" \\ 'Universidade Federal do Rio Grande do Sul (UFRGS), Porto Alegre/RS-Brasil \\ "Associação Sul Americana de Filosofia (ASAFTI) - Brasil
}

\section{RESENHA CRÍTICA}

KUSCH, Rodolfo. Esbozo de una Antropologia Filosófica Americana. Buenos

Aires: Ediciones Castañeda, 1978.

A obra intitulada Esboço de uma antropologia filosófica america$n a$ apresenta a problemática de pensarmos o(s) sentido(s) do humano desde a realidade latino-americana. Rodolfo Kusch, filósofo argentino, parte do pensamento popular, permeado por sabedorias marginalizadas para mostrar a riqueza e diversidade de um pensamento. A cultura e sua relação profunda com a terra são elementos centrais desta obra. Para tanto iremos analisar a trajetória seguida pelo pensador nesta obra para mostrar uma reflexão que traz contribuições importantes para pensarmos a educação e sua relação com o pensamento filosófico. Destacamos também a importância de resgatarmos a obra de um filósofo ainda pouco conhecido no Brasil, mas fundamental no debate sobre a interculturalidade e suas implicações no contexto latino-americano.

Günther Rodolfo Kusch nasceu e faleceu em Buenos Aires. Era filho de alemães radicados na Argentina. Graduou-se em filosofia pela Universidade de Buenos Aires em 1948. Atuou no Ministério da Educação de Buenos Aires na área de Psicologia Educacional e orientação profissional.

O propósito do autor na presente obra é organizar uma antropologia tendo como base as experiências do povo, formuladas a partir do silêncio que permeia a fala popular, que nem sempre é visível. Kusch busca pensar à margem da preocupação de uma definição de ser humano, que é própria da história do pensamento filosófico ocidental. Objetiva desconstruir o que já foi dito acerca do homem americano, no entanto, não afirma nem indica nenhum outro tipo de definição acerca do hu-

Educação \& Realidade, Porto Alegre, v. 39, n. 4, p. 1251-1257, out./dez. 2014. 1251 Disponível em: <http://www.ufrgs.br/edu_realidade> 
Esboço de uma Antropologia Filosófica Americana

mano. Ou seja, numa perspectiva heideggeriana, o filósofo enfatiza um humano incompleto, um ser não mais metafísico, mas que se constrói na exata medida que se faz. Kusch não tem a pretensão de resolver o problema do homem moderno a partir dos povos campesinos. O que deseja é recolocar o problema desde as origens de nossa sociedade, pois os povos do campo são um exemplo daqueles que romperam a homogeneidade da cultura dominante.

No primeiro capítulo da obra, intitulado Geocultura do Pensamento, Kusch analisa a importância da geocultura, afirmando que o pensar dos grupos humanos está condicionado pelo lugar, ou seja, faz referência a um contexto estruturado mediante a intersecção do geográfico com o cultural. Apresenta uma nova dimensão de cultura tomando-a não só como acervo, mas como atitude. Cultura é, sobretudo, decisão, afirmação existencial de um coletivo. É desse modo, que o autor coloca que todo diálogo de alguma forma é intercultural, implicando processos necessários de negociação com o Outro.

Um diálogo é antes de tudo um problema de interculturalidade. A distância física que separa os interlocutores e as voltas retóricas para entenderem-se, fazem referência a um problema cultural. Entre os interlocutores tende a existir uma diferença de cultivo, não no sentido de grau de culturalização construído por cada um, ou seja, que um seja mais culto que o outro, e sim antes de tudo no estilo cultural, ou melhor, no modo cultural que se encarnou em cada um (Kusch, 1978, p. 13).

A cultura encarnada mostra uma existência tecida pela dimensão cultural, pelo cultivo de um cotidiano feito por indivíduos e coletivos.

No segundo capítulo, O mito no pensamento popular, Kusch considera que é no pensamento popular e não no pensamento culto, que estão contidas as linhas gerais de pensar o humano em sua totalidade. Suas reflexões têm como base, entrevistas que realiza com pessoas simples do campo que orientam sua vida a partir da tradição mítica presente em suas culturas. Neste momento, o filósofo expõe sua metodologia de trabalho que consiste em quatro pontos fundamentais: 1) determinar as unidades simbólicas (aqui poderíamos traçar uma relação com as unidades de sentido); 2) a estruturação destas unidades; 3) as linhas de sentido que propiciam uma conexão entre estas unidades; e por último, 4) o contexto simbólico de todo discurso. Kusch salienta que o informante da pesquisa não é visto como um objeto a ser pensado, mas como um sujeito que define o próprio olhar interpretativo (e muitas vezes imperativo) do pesquisador. É assim que Ceferina e Sebastiana, interlocutoras de Kusch nesta obra, surgem não como personagens que emprestam voz a cultura popular, mas como traços fundamentais que nos ajudam a compor este esboço do humano. Esboço é um “[...] conjunto de traços iniciais, provisórios, qualquer trabalho ou obra em estado inicial"'; o humano é, portanto, esta obra inicial, incompleta, que

1252 Educação \& Realidade, Porto Alegre, v. 39, n. 4, p. 1251-1257, out./dez. 2014. Disponível em: <http://www.ufrgs.br/edu_realidade> 
no diálogo com o outro vai se reafirmando. O humano aqui não é um projeto pronto, é este fazer-se constante, amparado por uma terra que dramatiza a existência de cada um de nós.

A questão do humano aparece em sua obra não apenas para formular novas respostas a questão histórica da Filosofia, mas para fazer ressoar um silêncio que perpassa o sentido do humano. O esboço também é feito de silêncios que não são o resultado de um abafamento da voz dos povos, da imposição da mudez, mas resistência, de uma existência que fala pelo simples fato de estar (conceito este extremamente significativo para Kusch), arraigada a um solo que a nutre. Nesta obra acompanhamos o trabalho de um pensador em ler o cotidiano, no desafio de uma hermenêutica que coloca o pesquisador mesmo sob suspeita. Assim, a forma como as pessoas vão lendo a si mesmas, surge no texto em sua transparência, traçando novos sentidos a realidades que parecem já tão pré-determinas. Não há apenas algo a ser revelado na fala de suas interlocutoras, é a própria fala que define o movimento dos olhos de quem a lê.

Este é o desafio de um pensador em penetrar estas realidades inventando caminhos poéticos (talvez nada metódicos na visão da academia).

Ao longo de sua narrativa faz-se notar que para Kusch o novo está no popular e no indígena e não no chamado saber culto. Ao buscarmos um pensamento popular percebemos a possibilidade de descobrir um pensamento próprio, americano.

No capítulo terceiro, Mito e Racionalidade, Kusch continua tomando como referencial as entrevistas com representantes das culturas campesinas para analisar o mito e a racionalidade. Para o autor, no pensamento popular há uma religação com o absoluto, uma conjugação, um estar sendo; aspecto este que foi perdido pela cultura ocidental. Para recuperar o mistério de nosso estar temos que recuperar os sentidos de nossos símbolos e nossa relação com o solo, que de certa maneira traduzem a vinculação com o absoluto. Assim o filósofo nos apresenta uma diferença entre o mito narrado (oralidade) e o mito vivido. No mito narrado (objetividade), que se faz verbo, percebemos uma defasagem da palavra, e novamente o autor nos fala de uma palavra que transcende a si mesma, revelando um vazio, que não é ausência de sentido, mas algo que não cabe dentro da palavra. $\mathrm{O}$ mito vivido pode ser pensado como ritual, onde não se relata nada, apenas se vive. Desse modo, ele é anterior à palavra, quando esta chega, chega já em atraso. No entanto, estas duas dimensões se complementam. A narrativa também fala de uma realidade que expõe, na visão de Kusch, uma ontologia do contrato social. Ou seja, o que chamamos realidade se sustenta numa visão contratual da inteligência.

Se instrumentaliza uma teoria do conhecimento para determinar a solidez da realidade que, ao final de contas, já estava

Educação \& Realidade, Porto Alegre, v. 39, n. 4, p. 1251-1257, out./dez. 2014.1253 Disponível em: <http://www.ufrgs.br/edu_realidade> 
Esboço de uma Antropologia Filosófica Americana

dada desde sempre por uma estrutura contratual. Uma vasilha servirá sempre para tomar líquidos e nisso estamos todos contratualmente de acordo (Kusch, 1978, p. 53).

No quarto capítulo, Os arquétipos da economia popular, o autor enfatiza que a análise do popular fica em muitos momentos exclusivamente reduzida a uma dimensão econômica. As relações de trocas, de comercio que fazem parte do cenário popular (e são elementos fundamentais para entendermos este contexto) não podem se reduzir ao aspecto econômico, como um meio de sobrevivência diante de uma realidade que se mostra carente. O problema do homem assim seria transferido para um problema de coisas e é isto que se fez no ocidente nestes últimos tempos. Vive-se praticamente em um mundo coisificado, pois o pensamento e nossas preocupações se centram no econômico, convertendo-o em fator determinante de toda e qualquer leitura sobre o meio popular. $\mathrm{O}$ autor manifesta a necessidade de não só preocupar-se com a distribuição dos bens, mas adequar o econômico ao humano. Afirma que a ênfase no desenvolvimento é o mal da América Latina e postula que o fracasso em atingir essa meta se deve muito à ansiedade de impor-se uma hegemonia cultural. Propõe alguns caminhos para reflexão, embora não tenha o objetivo de dizer como deve ser a economia, apenas apresenta linhas gerais na esperança de dissolver o econômico no cultural. Conclui o capítulo afirmando que a fome não é só de pão, mas de uma incompletude do humano que dificilmente pode ser saciada.

No quinto capítulo, O arcaico no pensamento, o arcaico é compreendido como aquilo que escapa a determinação, ou melhor, "[...] aponta a uma determinação que se opõe ao tipo de determinação que exige uma consciência crítica" (Kusch, 1978, p. 74). Afirma que o arcaico aponta para algo que não exige uma consciência crítica, pois é um saber que está no nível do simbólico, ou seja, fora do âmbito da ciência. Enquanto a ciência tenta delimitar o objeto, o símbolo transcende ao determinado. Ao longo do capítulo o autor analisa detalhadamente a estrutura do símbolo e sua consolidação no ritual. É neste momento que podemos perceber as influências do pensamento de Paul Ricoeur na reflexão de Kusch.

O sexto capítulo, O que passa com o estar? Kusch parte de toda a fundamentação abordada nos capítulos anteriores para redimensionar o estar. Inicia contextualizando nossa América, ressaltando a base de nossa cultura assimilada, nossos hábitos de pensamento, em face à cultura que moldou nossa forma de estar no mundo. Movemo-nos entre as perspectivas populares, indígenas e a ocidental, contexto no qual se funda nosso modo de pensar como intelectuais. É dentro deste contexto que nos interrogamos a respeito de nosso estar. Nota-se a exigência colocada pelo autor em buscar a compreensão do que passa com o pensamento em geral, percebendo o humano que o sustenta com vistas a superar o vazio intercultural dentro do qual nos movemos. Kusch alerta para o fato de que somos marcados pela ocidentalização e em conse-

1254 Educação \& Realidade, Porto Alegre, v. 39, n. 4, p. 1251-1257, out./dez. 2014 Disponível em: <http://www.ufrgs.br/edu_realidade> 
quência, analisamos a realidade (com suas diferenças) a partir de um ponto de vista já internalizado, que surge como a única referência possível para pensarmos. O racional implica certa coerência e lógica dentro de um modo de pensar. Desse modo, pensar de outras formas significa agir irracionalmente, fora de uma ordem estabelecida que não aceita novas racionalidades. O pensamento popular nos apresenta outro modo de ser e isso nos exige outra postura filosófica e novas metodologias que sejam capazes de reconhecer o saber popular como um pensar legítimo. Dentro de uma lógica ocidental, construímos o saber ancorado na necessidade de definição, devemos sempre responder a pergunta pelo que é. Porém, no pensamento popular, como descreve nosso autor, tudo está, nem tudo é determinável, pois com relação aos deuses, por exemplo, não se pode afirmar isto é. Para recuperar o mistério de nosso estar temos que penetrar nos símbolos e no solo (gravidez de nosso pensar), e assim, recuperar nossa vinculação com o absoluto. Kusch interroga se a necessidade deste resgate se dá por que "[...] esta cultura está enferma de ser e perdeu o mistério de seu estar?" (Kusch, 1978, p. 99). O estar é tema de profunda análise ao longo de todo o capítulo sexto e continuará iluminando o restante da obra.

No sétimo capítulo, O humano na América, Kusch parte de duas interrogações: Como se desenvolve o homem na América? Que é o humano a partir do popular? Segundo ele, falta uma antropologia nova que não reduza o homem a compartimentos, mas que recupere sua essencialidade. Seu propósito é o de assumir o pensamento popular em toda sua profundidade, ou seja, esboçar uma antropologia do homem americano fora do julgamento já formulado pela cultura ocidental. Para tanto, devemos partir do descobrimento do humano desde seu próprio acontecer, regressando à consciência natural; isso implica em um recomeço. Neste capítulo o autor estabelece a distinção entre pensar e filosofar. Afirma que o pensar se refere a uma tomada de consciência, mas que é assistemática, enquanto que a filosofia assume apenas o papel metodológico (com suas regras), e apoio de nossa universalidade.

No oitavo capítulo, A importância do lugar filosófico, Kusch destaca a necessidade de que seja consolidada, no campo da filosofia, uma antropologia. Coloca que a antropologia filosófica consiste na intuição do ser humano como uma referência ao sentido do humano. Enfatiza que a concepção de homem, presente no ocidente, não a exaure. Devemos considerar a circunstância especial de estar na América, partindo não de abstrações já colocadas, mas do concreto ainda não refletido adequadamente. O autor afirma que assumir o lugar filosófico de onde se fala, ou seja, pensar a partir da América não significa apenas considerar o aspecto geográfico, mas vincular a reflexão em torno da circunstância, do dado, que permite a gestação deste pensar. O mistério da verdadeira Sofia, da fé ou da esperança, se dá quando recuperamos a globalidade do pensar, nesse processo perdemos a segurança que a racionalidade proporciona e entramos no terreno do simbólico.

Educação \& Realidade, Porto Alegre, v. 39, n. 4, p. 1251-1257, out./dez. 2014.1255

Disponível em: <http://www.ufrgs.br/edu_realidade> 
Esboço de uma Antropologia Filosófica Americana

No capítulo nono Fenomenologia da afirmação, o autor parte da afirmação de que o pensamento supõe um ato de concretização. Daí que, pensar os objetos e as coisas mostra-se como possibilidade para atingir a objetividade. Toda afirmativa inclui aquele que afirma. $\mathrm{O}$ ato em si de afirmar é de certa maneira afirmar-se, buscar a si próprio. Kusch analisa toda a ambiguidade do ato de afirmar algo e de afirmar-se a si mesmo, uma vez que esse ato carrega a subjetividade que conduz ao mistério. Sua reflexão orienta à suposição de uma alteridade, ou seja, afinal, quem funda o fundamento?

A vida humana transcorre nesse movimento que parte do que não se pode afirmar para o afirmável. Refletir então sobre o viver poderia nos levar a uma vida autêntica. Ao analisar o termo viver, o autor não define o que seja a vida, pois este termo transita entre o estar e o ser, entre uma área do impensável e do pensável. Por trás do conceito de vida há sempre "uma consciência de invalidez ontológica” (Kusch, 1978, p. 124).

No décimo capítulo, Estar-sendo como jogo, o autor centra aí toda a reflexão sobre o saber viver. Em que consiste então o jogo do viver? A fórmula de "estar-sendo" parece ser a chave para significar o viver. O jogo é a possibilidade que busca, indefinidamente, a coincidência feliz que constitui o humano em sua profunda liberdade e, ao mesmo tempo, condenação de não atingir o seu fundamento. Assim, percebe-se que não há diferença entre os humanos, independente de sua cultura e de seu contexto. A diferença está somente no modo de assumir o jogo do viver. A variabilidade das civilizações está justamente neste aspecto. Cada povo ensaia o mesmo jogo para as distintas áreas da objetividade, ou seja, outro modo de dizer isto é. Talvez o homem inverta a fórmula de ser homem e, ao invés de efetivar o estar sendo, caía na armadilha do ser para estar.

No último capítulo, O jogo e a prática do humano na América, o autor ao tentar determinar outro modelo do humano, analisa uma nova perspectiva de ver e tratar as dimensões humanas, como a educação, a cultura, a economia. Dedica vários parágrafos analisando a finalidade concreta da educação e em que ela consiste. O mesmo cuidado dispensa ao sentido da economia aclarando-a através das experiências vivenciadas.

Retoma a questão do humano, porém, nos diz que ao definirmos de uma única maneira o seu sentido, estaremos perdendo mais uma vez algo que para Kusch é fundamental: o humano deve ser pensado na sua relação sempre inacabada com o solo, ou seja, em sua dimensão existencial da cultura. Devemos desse modo, realimentar a transitoriedade do fundante, ganhar a inseguridade para atingir a plenitude do humano e, segundo o autor, a nossa própria missão na América. Isso supõe o campo das possibilidades do estar sendo. Toda reflexão aponta a uma gama do humano, mas também a sua indefinição radical, pois o fundamento nunca se concretiza. Conclui a obra em análise, afirmando que devemos assumir o paradoxo do viver e sua sacralidade.

1256 Educação \& Realidade, Porto Alegre, v. 39, n. 4, p. 1251-1257, out./dez. 2014. Disponível em: <http://www.ufrgs.br/edu_realidade> 
A obra de Kusch nos desperta a pensarmos a partir de uma postura que se aventura a sair de perspectivas filosóficas determinadas e fechadas do ocidente, superando padrões de pensamento que impedem a invenção de uma América descolonizada e de sujeitos que pensam desde seu contexto.

Recebido em 23 de julho de 2013 Aprovado em 22 de outubro de 2013

\section{Nota}

1 Houaiss. Dicionário Houaiss de Língua Portuguesa. São Paulo: Ed. Objetiva, 2009. p. 1196. verbete Esboço.

\section{Referências}

HOUAISS, Antônio. Dicionário Houaiss de Língua Portuguesa. São Paulo: Ed. Objetiva, 2009.

KUSCH, Rodolfo. Esbozo de una Antropologia Filosófica Americana. Buenos Aires: Ediciones Castañeda, 1978

Magali Mendes de Menezes é doutora em Filosofia, professora/pesquisadora da Universidade Federal do Rio Grande do Sul, FACED, área de atuação Filosofia da Educação. Presidente da Associação Sul Americana de Filosofia e Teologia Interculturais (ASAFTI)

E-mail:magalimm@terra.com.br

Neusa Vaz e Silva é doutora em filosofia Ibero-americana. Pesquisadora na área de filosofia Intercultural. Autora do livro: Teoria da Cultura de Darcy Ribeiro e a Filosofia Intercultural, Ed. Nova Harmonia.

E-mail: neusavazsilva@yahoo.com.br

Leonardo Castro Dorneles é mestre em Processo e Manifestações Cultural, graduado em Filosofia. Atua nas áreas de Filosofia e Educação, com ênfase em Interculturalidade.

E-mail: orcaoito@yahoo.com.br 